\title{
A double-crossover trial comparing the effects of topical carteolol and placebo on intraocular pressure
}

\author{
G R DUFF AND P A GRAHAM \\ From the Department of Ophthalmology, University Hospital of Wales
}

SUMmary The effect of topical carteolol $2 \%$ on the intraocular pressures of 12 patients suspected of having glaucoma was measured in a double-crossover trial of six weeks' duration. Carteolol produced a significant reduction in intraocular pressure $(p \leqslant 0 \cdot 001)$, when compared with placebo. This represented reductions of $11 \%$ and $14 \%$, after one and two weeks of treatment.

Recently introduced as treatment for raised intraocular pressure, carteolol is a non-selective betablocking agent with some intrinsic sympathomimetic activity. Previous placebo controlled studies ${ }^{1-3}$ are single-dose studies, and are discussed below. In this placebo controlled crossover study we demonstrated that topical carteolol $2 \%$, administered twice daily for two weeks, produced a significant reduction in intraocular pressure.

\section{Patients and methods}

Twelve subjects (nine female and three male) with normal visual fields were recruited from a glaucoma clinic. These subjects were thought to be at risk of developing glaucoma because of raised intraocular pressures, a family history of glaucoma, or cupping of their optic discs. Exclusion criteria were: confirmed open angle or closed angle glaucoma, any visual field defect, visual acuities of less than 6/12, corneal disease, a history of ocular surgery, asthma, chronic obstructive airways disease, cardiac failure, renal dysfunction, or current therapy with a beta-blocking agent.

Ethical approval was obtained from the hospital ethics committee. All subjects gave written informed consent, and underwent a pretrial physical examination and electrocardiograph. All subjects had their visual fields checked by a Goldmann perimeter (Armaly technique ${ }^{4}$ ) to ensure that they were normal. Those on ocular hypotensive treatment had their case histories and visual fields reviewed by an independent observer before their medication was stopped at least two weeks prior to the trial.

The subjects were randomly allocated to two

Correspondence to G R Duff, Department of Ophthalmology, University Hospital of Wales, Cardiff CF4 4XW. groups of six subjects each. There was a two-week treatment period followed by a two-week washout, then a final two-week treatment period. The subjects instilled drops in each eye twice daily throughout the trial. The subjects in group 1 were given carteolol $2 \%$ to the right eye and placebo drops to the left eye for two weeks, then placebo to both eyes for two weeks, then two weeks with placebo to the right eye and carteolol to the left eye. The subjects in group 2 were given the treatments in reverse order.

Intraocular pressures were measured at baseline and then weekly for six weeks. The intraocular pressure measurements were made by the same investigator at the same time of day (to within 20 minutes) approximately six to eight hours after treatment. All subjects completed the study. There were no withdrawals due to adverse effects, though soon after the onset of the trial one subject reported an episode of 'wheezing' which lasted 20 minutes.

Paired $t$ tests were used to confirm that there was no difference between the initial intraocular pressures of groups 1 and 2 . The difference between right and left eyes, and the difference between the eyes about to receive carteolol or placebo, did approach significance $(p=0.064$ and $p=0.093$, respectively), and this was therefore taken into consideration in the analysis of the results. The effectiveness of the washout period was confirmed by paired $t$ tests, as outlined by Hills and Armitage. ${ }^{5}$

In the crossover analysis the results for weeks 1 and 5 (or weeks 2 and 6) were compared. If symmetry of effect between the right and left eyes is not taken for granted, the sum of the effects in the two treatment periods was calculated - that is, $(\mathrm{R} 1-\mathrm{L} 1)-(\mathrm{R} 5-\mathrm{L} 5)$ for each subject, where $R 1$ is the intraocular pressure in the right eye for a given subject at the end of week one, and so on. The two groups were then compared 
Table 1 Comparison of IOP between carteolol and placebo in 12 subjects, with allowance for possible asymmetry between eyes. Mean pretreatment $\mathrm{IOP}( \pm S E)$ for 12 subjects was $21( \pm 1 \cdot 2) \mathrm{mmHg}$

\begin{tabular}{|c|c|c|c|c|c|}
\hline Weeks to be compared & $d f$ & $\begin{array}{l}\text { Estimated difference in IOP, } \\
\text { carteolol minus placebo }\end{array}$ & $95 \%$ confidence limits & $t$ & $p$ \\
\hline $\begin{array}{l}1 \text { and } 5 \\
2 \text { and } 6 \\
1 \text { adjusted for } 0 \\
2 \text { adjusted for } 0\end{array}$ & $\begin{array}{r}10 \\
10 \\
9 \\
9\end{array}$ & $\begin{array}{l}-1 \cdot 17 \\
-2 \cdot 08 \\
-2 \cdot 82 \\
-2 \cdot 16\end{array}$ & $\begin{array}{l}-1.78 \text { to } 0.55 \\
-2.70 \text { to }-1.47 \\
-4.03 \text { to }-1.61 \\
-3.70 \text { to }-0.62\end{array}$ & $\begin{array}{l}-4 \cdot 24 \\
-7 \cdot 57 \\
-5 \cdot 29 \\
-3 \cdot 18\end{array}$ & $\begin{array}{r}0.001 \\
<0.001 \\
<0.001 \\
<0.01\end{array}$ \\
\hline
\end{tabular}

by a 2-sample $t$ test $(10 \mathrm{df})$; similarly for weeks 2 and 6.

\section{Results}

Carteolol $2 \%$ produced a significant reduction in intraocular pressure. Whether the data for weeks 1 and 5 or those for weeks 2 and 6 are analysed, the results were qualitatively the same. If only the first treatment period is considered, a significant result was still obtained. In this case the difference between carteolol and placebo was $2.82 \mathrm{mmHg}$ for week 1 , and $2.16 \mathrm{mmHg}$ for week 2 , which represent reductions of $14 \%$ and $11 \%$ respectively. The mean $( \pm$ SE) pretreatment intraocular pressure for all 12 subjects was $20 \cdot 7( \pm 1 \cdot 15) \mathrm{mmHg}$. The results are summarised in Table 1.

\section{Discussion}

In the present study the subjects received active treatment to one eye and placebo to the other. After a washout period the treatments were reversed. This double-crossover design does make the study an extremely efficient one, though the assumption is made that carteolol has no significant effect on the contralateral placebo treated eye. Any such effect will tend to decrease the apparent treatment effect, so that both our estimated difference between active and placebo and its significance levels are conservative.

We obtained reductions in intraocular pressure of $14 \%$ and $11 \%$ after one and two weeks' treatment. This is in close agreement with Horie et al.,$^{6}$ who in a double-blind crossover study comparing timolol and carteolol found reductions of $10 \%$ and $13 \%$ after two and four weeks on carteolol $2 \%$ (mean pretreatment intraocular pressure $( \pm \mathrm{SE})$ was $23.25( \pm 0.67)$ $\mathrm{mmHg}$ ).

There are three previous publications in which the effects of topical carteolol and placebo on intraocular pressure are compared, though these are all singledose studies.

Gregory and Martin' examined the effect of carteolol on intraocular pressure in six normal

*Calculations based on data supplied by manufacturer. volunteers. Carteolol was administered as a drop of $2 \%$ solution and as an oral dose of $20 \mathrm{mg}$. The differences in the effects of placebo and topical carteolol on intraocular pressure did not reach significance (maximum difference in effect (placebo-carteolol) $=2.8 \mathrm{mmHg} ; \mathrm{df}=10, t=-1.275$, $\mathrm{p}=0 \cdot 231){ }^{*}$

Kitazawa et al. ${ }^{2}$ studied the ocular hypotensive effect of topical carteolol in subjects with raised intraocular pressure. The peak effect of carteolol $1 \%$ and $2 \%$ occurred at 2 hours; significant reductions in intraocular pressure were obtained from two to three hours with carteolol $1 \%$, and from zero to six hours with carteolol $2 \%$. There was a $10 \%$ reduction in intraocular pressure six hours after the administration of carteolol $2 \%$, which is in agreement with the result of our multidose study.

We are unable to comment on the 12-hour control of intraocular pressure, because we measured intraocular pressures six to eight hours after dosage. Nevertheless, when comparing carteolol $2 \%$ with placebo, neither Kitazawa et al. ${ }^{2}$ nor Negishi et al. ${ }^{3}$ obtained significant reductions in intraocular pressure at eight hours, which raises some doubt about the suitability of a twice daily regimen when using carteolol to treat raised intraocular pressure.

We are grateful to Dr R G Newcombe, of the Department of Medical Computing and Statistics, University of Wales College of Medicine, for his help and advice in the analysis of this study.

\section{References}

1 Gregory J, Martin BK. Ocular effects and pharmacokinetics of carteolol in volunteers. Invest Ophthalmol Vis Sci 1986; 27 (suppl): 349.

2 Kitazawa Y, Azuma I, Takase M, Komemushi S. Ocular hypotensive effects of carteolol hydrochloride in primary open angle glaucoma and ocular hypertensive patients. Nippon Ganka Gakkai Zasspi 1981; 85: 798-804.

3 Negishi C, Ueda S, Kanai A, et al. Effect of beta-blocking agent, carteolol, on healthy volunteers and glaucoma patients. Nippon Ganka Gakkai Zasshi 1982; 85: 57-66.

4 Armaly MF. Selective perimetry for glaucomatous defects in ocular hypertension. Arch Ophthalmol 1972; 87: 518-24.

5 Hills M, Armitage P. The two period cross-over clinical trial. $\mathrm{Br} J$ Clin Pharmacol 1979; 8: 7-20.

6 Horie T, Takahashi O, Shirato S, Kitazawa Y. Comparison of ocular hypotensive effects of carteolol eye drops and timulol eye drops. Jpn J Clin Ophthalmol 1982; 36: 1065-70.

Accepted for publication 27 November 1986. 